\title{
Prática Educativa na Biblioteca Escolar: um trabalho a partir do gênero textual lenda ${ }^{1}$
}

\author{
Educational practice in the school library: a work from the textual genre legend ${ }^{l}$
}

\begin{abstract}
Lucas Veras de Andrade
Especialista em Supervisão Educacional (UESPI).

Docente das Séries Iniciais do Ensino Fundamental da Secretaria Municipal de Educação de Teresina (SEMEC).

E-mail: lukkandrade18@hotmail.com
\end{abstract}

\section{Resumo}

Este artigo relata o trabalho realizado com o gênero textual lenda na biblioteca da escola municipal Alda Rodrigues Neiva, localizada no município de Teresina (PI). O projeto teve como objetivo geral: Ampliar as perspectivas de ensino-aprendizagem para além do trabalho em sala de aula, dando ênfase ao contexto da biblioteca escolar e o seu uso a partir de atividades desenvolvidas na mesma. O percurso metodológico foi elaborado a partir das atividades propostas, sendo estas desenvolvidas sempre após o intervalo do período da manhã no espaço da biblioteca escolar. Ainda nos utilizamos da observação participante e do diário de campo como forma de nos possibilitar um melhor entendimento das análises e dos resultados de forma qualitativa. Apesar de alguns entraves no decorrer do desenvolvimento das atividades, o projeto se mostrou bem relevante principalmente no que diz respeito ao desenvolvimento de atividades coletivas com os discentes e usabilidade da biblioteca escolar, uma vez que foi demonstrado por alguns alunos o desconhecimento e a função deste espaço no contexto educacional evidenciado.

Palavras-Chave: Gênero Lenda. Biblioteca Escolar. Leitura. Escola Municipal Alda Rodrigues Neiva.

\begin{abstract}
This article describes the work done with the textual genre legend in the library of the municipal school Alda Rao Neiva, in the municipality of Teresina (PI). The project had as general objective: to broaden the perspectives of teaching and learning beyond the classroom work, emphasizing the context of the school library and its use from activities carried out in the same. The methodological path was drawn from the activities proposed, these being developed always after the interval of the mornings in the school library space. We still use of participant observation and field journal as a way to enable a better understanding of the analyses and the results qualitatively. Despite some obstacles in the course of the development of the activities, the project turned out to be quite relevant particularly as regards the development of collective activities with the students and usability of the school library once it has been demonstrated by some students disregard and the function of this space in the educational context evidenced.
\end{abstract}

Keywords: Gender Legend. School Library. Reading. Municipal School Alda Rodrigues Neiva.

\footnotetext{
${ }^{1}$ Artigo resultante do Projeto "Biblioteca Escolar e Práticas Educativas: dinamizando este espaço a partir do gênero lenda", desenvolvido na Escola Municipal Professora Alda Rodrigues Neiva e apresentado no I Seminário de Socialização de Experiências com Projetos do Centro de Formação Odilon Nunes da Secretaria Municipal de Educação de Teresina (SEMEC).
}

Bibl. Esc. em R., Ribeirão Preto, v. 4, n. 1, p. 75-95, 2015. 
Prática Educativa na Biblioteca Escolar: um trabalho a partir do gênero textual lenda

\section{Introdução: a biblioteca escolar em foco}

Este artigo relata a experiência de um projeto educativo desenvolvido na biblioteca escolar da Escola Municipal Professora Alda Rodrigues Neiva, sediada no município de Teresina (PI). A ideia do mesmo surgiu a partir de uma oficina na formação continuada de Língua Portuguesa, ofertada pela Secretaria Municipal de Educação de Teresina, no Centro de formação Odilon Nunes, cuja temática versou sobre as lendas folclóricas como gênero textual.

Nos encontros da referida formação, refletimos acerca do gênero e da forma como poderia ser trabalhado em sala de aula, bem como em outros espaços dentro do ambiente escolar. Desse modo, buscamos a interdisciplinaridade com o campo científico da área da Ciência da Informação, especificamente o campo da Biblioteconomia como forma de dar voz e vez a um componente do espaço escolar muito importante na conjuntura da aprendizagem dos educandos e que cada vez mais vem sendo esquecido, que é a biblioteca escolar.

Nossa proposta de interdisciplinaridade, a princípio parte da familiaridade do idealizador deste projeto com as áreas que estão envolvidas, uma vez que este além de ser Professor de Língua Portuguesa, ainda tem formação em Bacharelado em Biblioteconomia. O outro aspecto a ser mencionado é que a biblioteca escolar deve ser entendida como um organismo vivo, cujo papel é promover a leitura dos estudantes e professores, desenvolvendo suas aprendizagens e o uso da informação de forma crítica. Nosso público alvo foram os alunos do $4^{\circ}$ ano do Ensino Fundamental da referida escola, com faixa etária de 8 e 9 anos, uma vez que esta é a turma em que o proponente deste relato encontra-se desenvolvendo sua atividade docente.

O projeto foi desenvolvido na biblioteca que está momentaneamente desativada pela ausência de um profissional capacitado (bibliotecário escolar) que possa executar projetos de incentivo à leitura, assim como promover sua utilização, interligando-a com as atividades desenvolvidas nas salas de aulas pelos professores de forma pedagógica e lúdica.

Desse modo, buscou-se com o projeto de maneira geral: Ampliar as perspectivas de ensino-aprendizagem para além do trabalho em sala de aula, dando ênfase ao contexto da biblioteca escolar e o seu uso a partir de atividades desenvolvidas na mesma. Objetivou-se ainda: 1) Proporcionar aos alunos do $4^{\mathrm{a}}$ ano, um aprofundamento teórico e conceitual sobre a temática lenda, enquanto manifestação de valorização da cultura popular; 2) Permitir aos discentes o conhecimento de diversas lendas que puderam ser aprofundadas a partir da leitura 
Lucas Veras de Andrade

das obras; 3) Oportunizar ao alunato a vivência com os livros e a leitura, permitindo aos mesmos a possibilidade de se constituírem como leitores; 4) Desenvolver habilidades de escrita, artísticas e de trabalho em grupo nos alunos e por fim; 5) Reativar a biblioteca escolar da escola em questão.

Dessa forma, o projeto se tornou relevante na medida em que oportunizou aos alunos da referida instituição de ensino à vivência no espaço da biblioteca escolar, despertando o prazer pela leitura, formando-os como leitores e principalmente integrando o espaço desta ao processo de ensino/aprendizagem, favorecendo a consolidação do almejado prazer de ler.

Nossa proposta ainda busca reativar este espaço na medida em que é de nossa intenção continuar desenvolvendo projetos desta natureza no ambiente da biblioteca, mesmo que de forma esporádica, pois sabemos que como docentes ficamos limitados quanto à usabilidade deste espaço de forma organizada, no sentido de possibilitar ao educando a vivência de toda a potencialidade que este ambiente pode favorecer a aprendizagem dos alunos.

Uma vez explicitado em que consistem nossos objetivos, estruturamos nosso relato em sete partes, sendo a primeira a introdução em que explanamos nossa intenção de tornar o ambiente da biblioteca escolar como um espaço de singular importância dentro do contexto educacional. Na segunda, temos o delineamento metodológico onde evidenciamos o percurso percorrido por nós até a culminância do projeto na atividade sete.

Logo após, temos uma breve contextualização sobre a biblioteca escolar e suas funções no contexto educacional. Em seguida tecemos algumas considerações sobre o gênero textual lenda. Na quinta pontuamos as atividades desenvolvidas e o detalhamento destas. $\mathrm{Na}$ sexta, demonstramos as análises e os resultados onde pautamos o olhar dos alunos acerca das atividades desenvolvidas e nossas impressões diante destas. Na última parte, apresentamos as considerações finais em que retomamos nossas observações e os principais resultados do caminho percorrido. 
Prática Educativa na Biblioteca Escolar: um trabalho a partir do gênero textual lenda

\section{Delineamento Metodológico}

O percurso metodológico foi elaborado a partir das atividades propostas, sendo estas desenvolvidas sempre após o intervalo do período da manhã no espaço da biblioteca escolar. Nesse sentido, a turma do referido ano foi dividida em cinco grupos, cabendo a cada um a responsabilidade pelo desenvolvimento de uma atividade no contexto de cinco entre as sete pensadas no projeto. Esta forma de trabalho a nosso ver, reduziu a apatia dos discentes frente ao desenvolvimento das etapas e atividades, minimizou ainda a possibilidade de indisciplina e favoreceu o aprofundamento e desempenho dos grupos formados, uma vez que cada um pôde dar o melhor na culminância do que se propôs.

A primeira atividade empreendida foi dividida em quatro etapas em que tivemos: a apresentação da ideia do projeto aos alunos em sala, fase em que obtivemos a colaboração de todos bem como o interesse pela participação ativa nas atividades desenvolvidas. Logo após, tivemos o levantamento prévio acerca do conhecimento do gênero em questão pelos discentes. Nesta buscamos demonstrar a ideia de lenda, bem como o conhecimento das mesmas pelos educandos, demonstrando se este é evidenciado na subjetividade destes mais em âmbito local ou nacional. Isto se evidenciou a partir de um questionário elaborado para o determinado fim.

Depois tivemos uma visita orientada a biblioteca escolar, onde fizemos a localização e o levantamento do acervo bibliográfico do gênero lenda. Por fim, escolhemos democraticamente a partir do olhar dos alunos, as obras e as respectivas lendas que foram trabalhadas no projeto.

A segunda atividade foi desenvolvida a partir do conhecimento prévio levantado na etapa de número dois na atividade um, acerca da temática estudada pelos alunos. Mediante tais procedimentos, aprofundamos o conteúdo com aula dialogada e expositiva em sala, apresentando-os conceitos e características do gênero em discussão, enfatizando que esse surgiu da oralidade, tendo origem popular e buscando a valorização da cultura de determinado povo e/ou região.

As três atividades a seguir estiveram interligadas, sendo a de número três a que permitiu o conhecimento necessário para o desenvolvimento das duas posteriores. $\mathrm{Na}$ atividade três propusemos a um aluno a contação para os colegas de uma lenda que foi mediada por nós. A atividade quatro dividiu-se em duas partes: a primeira elaborou-se um texto coletivo que foi desenvolvido por nós a partir da contação de uma lenda. Nesta os alunos 
Lucas Veras de Andrade

puderam expressar suas opiniões e demonstrar a percepção sobre a lenda redigida em forma de texto coletivo no quadro de acrílico. Esta parte subsidiou a fundamentação para o desenvolvimento do texto individual, uma vez que o reconhecimento e atenção dados aos conhecimentos dos alunos por nós na elaboração do texto coletivo, possibilitou a percepção dos discentes na produção bem como os motivou para que se sentissem seguros na realização da escrita individual.

A atividade cinco foi desenvolvida com base na atividade três, nessa os alunos do grupo responsável pela elaboração do desenho deixaram a imaginação fluir, pois os mesmos foram incitados a reinventarem uma lenda por meio de um desenho a partir da contação de um colega escolhido pelo grupo. Nesta os mesmos estiveram desprovidos de regras.

$\mathrm{Na}$ atividade seis, escolheu-se uma lenda e a partir dela elaborou-se um teatro que a turma apresentou por meio de varas a história escolhida. Esta atividade serviu de ensaio para atividade sete (uma lenda dramatizada) que os alunos apresentaram no pátio da escola pela inviabilidade do espaço físico da biblioteca escolar.

Vale ressaltar que as atividades quatro e cinco tiveram como culminância a exposição dos trabalhos em murais que estiveram expostos para o conhecimento dos demais alunos da instituição de ensino onde o projeto foi realizado. Ainda nos utilizamos da observação participante e do diário de campo como forma de nos possibilitar um melhor entendimento das análises e dos resultados de forma qualitativa.

Laville (1999) compreende a observação participante como algo que permite ao pesquisador ver longe, e considerar várias facetas dentro de um contexto. Nesse sentido, ela nos foi de grande relevância por permitir compreender a rotina dos alunos na realização do projeto, através de fatos e ocorrências que se apresentaram gestualmente pelos educandos.

O diário de campo foi outra forma que nos possibilitou colher dados riquíssimos. Por meio do diário registramos todos os momentos do projeto: fatos, o comportamento dos alunos, os conflitos no decorrer das atividades, ou seja, tudo aquilo que se fez presente durante a sua execução. Nesta perspectiva, buscamos fundamentação em Trivinõs (1987, p. 155) que "considera que as anotações de campo podem representar as primeiras buscas espontâneas de significados, as primeiras expressões de explicações”. 
Prática Educativa na Biblioteca Escolar: um trabalho a partir do gênero textual lenda

\section{Biblioteca Escolar e seu papel no contexto educacional}

Na perspectiva de Soares, Andrade e Sales (2011, [p. web]) a biblioteca escolar deve ser entendida como "uma extensão da sala de aula, elemento indispensável para mediação e/ou transformação da informação em conhecimento". A entendemos como um espaço de liberdade de ideias que deve complementar as atividades docentes, servindo de suporte ao processo de ensino/aprendizagem, criando elos entre os discentes e a informação e a relação que os mesmos estabelecem com ela.

Ainda fazemos menção à biblioteca escolar como um espaço de desenvolvimento de habilidades e principalmente absorção, uso e escolha de informações, competências essas indispensáveis ao contexto atual da chamada sociedade da informação. Segundo Campello (2005, p. 17-18) o papel da biblioteca na perspectiva dos Parâmetros Curriculares Nacionais é:

a) [Possibilitar] um programa de leitura eficiente, que forme leitores competentes e não leitores que façam isso de forma esporádica e saibam compreender o que lêem e desenvolvam praticas de intertextualidade;

b) [Deve ser] lugar apto a influenciar o gosto pela leitura;

c) [Local] de aprendizagem permanente, um centro de documentação onde se encontre informações que irão responder aos questionamentos levantados dentro das diversas áreas curriculares;

d) Desenvolver atitudes de cidadania.

Podemos observar que são imensuráveis as funções da biblioteca no contexto educacional, que vão desde o desenvolvimento de habilidades nos discentes, os fundamentando no que concerne ao ensino/aprendizagem até a consolidação de habilidades que possibilitam aos educandos a possibilidade de ser tornarem leitores críticos que se utilizam da informação de forma racional.

Assim, os benefícios que são trazidos pela biblioteca escolar desde que integrada ao programa educacional são imensuráveis. Agora precisamos estar atentos para que não seja vista como uma peça decorativa, como afirma Silva (2009). Ela deve ser ativa e permitir a toda a comunidade da escola todas as possibilidades de se refletir, sedimentar e ampliar a compreensão do mundo (SILVA, 2009, p. 118). A seguir explanaremos breves considerações sobre o gênero textual lenda. 
Lucas Veras de Andrade

\section{Gênero textual lenda: breve contextualização}

Segundo Oliveira e Castro (2008, p. 74) "Desde a antiguidade as pessoas inventam e contam histórias", seja para compartilhamento de uma ideia com alguma intenção, ou para transmitir experiências. Daí surge às lendas, narrativas populares que a partir de uma memória coletiva é contada e recontada, perpassando por diversas gerações.

As lendas possuem como características, a mistura de aspectos fantasiosos com elementos da realidade que buscam explicar a ocorrência de fatos e/ou eventos ao longo da vida de um povo ou pessoas de forma sobrenatural. Vários podem ser os tipos de lendas como podemos observar:

○ Lenda Religiosa: gira especificamente sob a figura de santos e seus comportamentos.

○ Lenda Histórica: Explica naturalmente o surgimento de lugares, civilizações, nações e países.

- Lenda Naturalística: explana como se dá o surgimento dos elementos da natureza, bem como elementos geográficos. Esse tipo de lenda tornou-se popular principalmente no meio indígena.

Enquanto gênero textual, a lenda se organiza mediante a seguinte estrutura: 
Prática Educativa na Biblioteca Escolar: um trabalho a partir do gênero textual lenda

QUADRO A: Quadro explicativo da estrutura do gênero textual lenda.

\begin{tabular}{|c|c|c|}
\hline \multirow{5}{*}{$\begin{array}{l}\text { Contexto } \\
\text { de } \\
\text { Produção }\end{array}$} & Autoria & Sem Autoria \\
\hline & Suporte & $\begin{array}{l}\text { Fontes de Informações } \\
\text { diversas: livros, sites etc. }\end{array}$ \\
\hline & Tema & $\begin{array}{l}\text { História de Santos, tradição } \\
\text { e cultura de um povo. }\end{array}$ \\
\hline & Finalidade & $\begin{array}{l}\text { Explicar acontecimentos } \\
\text { misteriosos. }\end{array}$ \\
\hline & Público-Alvo & $\begin{array}{l}\text { Curiosos e pesquisadores da } \\
\text { cultura popular. }\end{array}$ \\
\hline \multirow{6}{*}{$\begin{array}{c}\text { Estrutura } \\
\text { Composição / Gráfica }\end{array}$} & Tempo & Sem referência de tempo. \\
\hline & Personagens & $\begin{array}{l}\text { Na grande maioria das } \\
\text { narrativas são os seres } \\
\text { humanos. }\end{array}$ \\
\hline & & $O$ ponto central de interesse \\
\hline & Enredo & é o caráter explicativo. \\
\hline & Gênero & Narrativo. \\
\hline & Espaço & Definido. \\
\hline \multirow{4}{*}{ Marcas Linguísticas } & Verbos & Passado. \\
\hline & Linguagem & Formal. \\
\hline & Foco Narrativo & $3^{o}$ pessoa. \\
\hline & Subjetividade & Adjetivos. \\
\hline
\end{tabular}

Fonte: Adaptação de Oliveira e Castro (2008, p.75).

Dentro desse contexto estrutural, ainda podemos mencionar que suas histórias são curtas e a linguagem é de fácil entendimento, sendo seu foco central a explicação das coisas. As lendas são de fundamental importância, porque enaltecem a sabedoria popular e evidenciam a questão identitária por possibilitarem a compreensão da história de povos e civilizações. A seguir, apresentaremos as atividades desenvolvidas, bem como seu detalhamento. 


\section{Atividades: o percurso percorrido}

Aqui explanaremos mediante nossas observações, o passo a passo da execução das atividades com detalhamento:

\section{Atividade de Número 1}

Nesta, como já mencionado, dividimos em quatro etapas. Na primeira tivemos a exposição dos objetivos do projeto bem como a explicação de cada atividade em sala de aula para os educandos. Como resposta, percebemos curiosidade diante do explanado e boa receptividade, requisitos fundamentais para sua realização com sucesso. Com relação aos conhecimentos prévios levantados, os alunos demonstraram grande conhecimento a respeito das lendas nacionais.

Logo após tivemos a visita orientada á biblioteca da Escola Municipal, lócus das atividades. Nela nos foi demonstrado muito entusiasmo pelos educandos e em questionário aplicado aos discentes, pudemos evidenciar que muitos ali adentravam naquele espaço pela primeira vez, ou seja, utilizavam o espaço da biblioteca como complemento de atividades de sala de aula para a melhoria da aprendizagem, representando assim, um percentual de $89 \%$ (oitenta e nove por cento) dos alunos participantes.

Uma vez explicitado em que consistia o projeto e evidenciado a importância do uso da biblioteca escolar para a aprendizagem dos alunos, a turma escolheu seis alunos os quais procederam à seleção bibliográfica que contemplasse a temática lenda no contexto de 1200 (mil e duzentos) títulos que a biblioteca mantém em seu acervo. Como forma de não permitir a ociosidade do restante da turma, elaborou-se uma atividade de leitura referente ao surgimento das lendas para que os demais pudessem se aprofundar sobre o assunto em pauta.

Após alguns momentos foram encontrados 10 (dez) obras, que contemplavam lendas internacionais, nacionais, regionais e locais. Nessas pudemos detectar 34 (trinta e quatro) manifestações de lendas e após leitura expositiva de todas pelo professor, foram escolhidas previamente por eleição democrática pelos educandos 14 (quatorze) e dessas, optou-se por cinco para serem trabalharmos no decorrer das atividades. 
Prática Educativa na Biblioteca Escolar: um trabalho a partir do gênero textual lenda

Um fato nos chamou atenção. No momento da escolha prévia das lendas, a turma de imediato descartou as lendas internacionais. E em afirmação na forma de réplica a nossa indagação para justificativa de tal ato, um dos alunos responde: "Porque a gente só gosta do que é daqui!". Isso nos denota um sentimento de identidade e valorização da própria cultura pelos alunos, uma vez que a decisão pelo descarte destas foi tomada em conjunto, embora a afirmação tenha sido feita de forma individualizada. A seguir, evidenciaremos todas as etapas acima mencionadas. A título de informação, resumiremos brevemente as lendas selecionadas pelos discentes. Como aporte teórico, utilizamos os escritos de Villas Boas (2000), Rodrigues (2004) e Cascudo (2009), entre outras fontes de informação como: periódicos e bases de dados.

\section{$\underline{\text { Lendas Nacionais }}$}

\section{$\checkmark$ Boto Cor de Rosa}

É uma lenda da região amazônica. Conta o povo que o boto ao anoitecer com um poder especial transforma-se em um belo rapaz, alto e forte. Com seu enorme poder galanteador, logo envolve as mulheres ribeirinhas, seduzido-as. Após esta etapa, logo convida as moças para um passeio ou um banho de rio deixando-as grávidas. Ao amanhecer ele se transforma novamente em boto. Dizem os mais velhos que dependendo do sexo do bebê, ou seja, ser for homem, o boto retorna e o leva para virar boto e a mãe jamais o vê-lo novamente.

\section{$\checkmark$ Vitória Régia}

É uma lenda de origem Tupi. Contam que há muitos anos em uma tribo indígena, Jaci deusa da lua, ao anoitecer descia do céu, e a beira do rio escolhia as índias mais bonitas e virgens que banhavam lá e as levavam ao céu transformando-as em estrelas. Um dia a linda Naiá, uma jovem índia que sonhava com este encontro, parou para descansar a beira do rio depois de uma caçada. Ao anoitecer viu na superfície a imagem da deusa que não passava do reflexo da lua. Eufórica, jogou-se ao rio e afogou-se. A deusa entristecida pelo ocorrido e cheia de culpa, resolveu recompensar a bela jovem decidindo transformá-la em uma estrela diferente, uma estrela da água. Surge então à lenda da vitória régia, planta aquática que possui flores perfumadas e brancas que só se abrem à noite.

Bibl. Esc. em R., Ribeirão Preto, v. 4, n. 1, p. 75-95, 2015. 


\section{$\underline{\text { Lendas Piauienses }}$}

\section{$\checkmark$ Cabeça-de-Cuia}

É a lenda de maior repercussão em Teresina, capital do Piauí. Conta à história de um jovem chamado Crispim (pescador) que morava com sua mãe (viúva) em uma vila chamada Poti. Certo dia, depois de uma pescaria mal sucedida, volta para casa sem nada em sua rede. Enraivecido, espanca sua mãe com uma ossada que a mesma tinha preparado para o almoço. Debruçada e antes de falecer, lança uma maldição sobre seu filho, dizendo a ele que se transformaria em um monstro chamado cabeça-de-cuia, com cabeça volumosa e que viveria a vagar no encontro dos rios que banham a cidade de Teresina (o rio Poti e o rio Parnaíba). A maldição só se desfaria se devorasse sete mulheres virgens chamadas de Maria.

\section{$\checkmark \quad$ Pé-de-Garrafa}

Conta à história de um animal horrendo, cuja característica principal é o pé que se confunde com um fundo de uma garrafa. Comenta o povo que estavam dois amigos caçadores a caminhar pela mata e um deles se perdeu do companheiro. O que se perdeu começou a gritar pelo amigo. Uma voz começou a responder. Acreditando ser o amigo, o caçador perdido aproximou e viu um terrível animal parecido com um lobo. O homem no desespero para se esconder, subiu em uma árvore de onde percebeu o bicho rondando embaixo enfurecido. Ao amanhecer desceu, mas só viu o rastro do tal animal na forma de fundo de garrafa. Desde então, quando alguém se perde na mata, evita-se gritar, temendo-se a aparição do pé-degarrafa.

\section{$\checkmark \quad$ Baleia Adormecida}

É uma lenda específica da cidade de Valença no Piauí. Diz à lenda que a igreja matriz da cidade foi construída em cima de um lençol marítimo. Proferem os mais antigos que lá mora uma baleia adormecida. Acredita-se que quando a baleia desperta, a mesma estremece as paredes da igreja e assusta toda a população da cidade. 
Prática Educativa na Biblioteca Escolar: um trabalho a partir do gênero textual lenda

Uma vez descrita à atividade de número 1, se detalhará a seguir a atividade de número 2 em que apresentaremos como se deu a aula expositiva sobre o gênero lenda, bem como os principais encaminhamentos para as atividades posteriores.

\section{Atividade de Número 2}

Nesta atividade tentamos dar respaldo teórico aos alunos para que estes pudessem se aprofundar no que concerne ao gênero textual aqui estabelecido. Desse modo, nossa aula foi planejada com base nos conhecimentos prévios levantados na etapa 2 , da primeira atividade.

Segundo nossas observações e com base nas informações coletadas, sentimos necessidade de esclarecermos aos discentes sobre: a diferença entre mito e lenda, momento em que pontuamos as diferenças principalmente com relação aos personagens. Nesse sentido, explanamos inicialmente com relação ao primeiro tipo de história ou gênero, deixando claro que este surge da necessidade de explicar a origem das coisas, e que o divino está sempre acima da natureza humana. Frisamos também que a lenda é uma narrativa imagética de tradição oral, contada e recontada por várias gerações. Esclarecemos ainda, que os personagens do primeiro gênero são sempre deuses e da lenda são personagens reais que a partir de uma maldição ou encantamento são transformados em animais, plantas ou outros seres da natureza.

Com o decorrer da discussão, outros questionamentos foram surgindo como: As lendas são reais?, Como as lendas se tornam lendas?. Tais perguntas foram respondidas a partir das próprias falas dos alunos, ou com o desenvolvimento de atividades que não estavam previstas no projeto. Um exemplo disso foi a maneira lúdica e divertida de explicarmos o processo pelo qual passa uma história até torna-se lenda.

Nesta atividade extra, buscamos situar os alunos no tempo e no espaço para que tivessem a percepção de que histórias tornam-se lendas, após se perpetuarem por vários anos, tornando-se assim, memorável na cultura de um povo. Logo após a esta, buscamos ainda melhorar a explicação por meio da brincadeira lúdica telefone sem fio, dinâmica que consiste na internalização da ideia de temporalidade, buscando por meio de uma frase dita na brincadeira passar a concepção de memória. Cada aluno passaria a frase para o colega e assim, a ideia de lenda como algo de transmissão oral e perdurável por tempos, estaria concretizada. 
Lucas Veras de Andrade

Logo após encerrarmos a brincadeira, fizemos por votação os encaminhamentos para as próximas atividades do projeto. Desse modo, ficou acertada mediante a opinião dos alunos, a lenda que seria trabalhada em cada atividade. Também nesta atividade, fez-se a divisão dos grupos e reforçou-se a responsabilidade que cada um teria na realização das tarefas. A escolha dos participantes de cada um dos grupos se deu de forma em que o professor deixou livre, ou seja, a cargo das crianças. Podemos perceber que a atividade que envolve desenhos, ou seja, a atividade de número 5 foi a que mais chamou atenção dos alunos. Nossa afirmação se fundamenta no número de estudantes que se mostraram interessados no desenvolvimento desta, representando um percentual de $38 \%$ (trinta e oito por cento) do total de alunos da turma, seguidas da atividade referente ao teatro com varas que representou $27 \%$ (vinte e sete por cento).

\section{Atividade de Número 3 e 4}

Como já mencionado, estas atividades estiveram interligadas, uma vez que a atividade de número 3 serviu para fundamentar e permitir o desenvolvimento das habilidades necessárias para que os educandos realizassem as atividades 4 e 5 .

Ao mesmo tempo em que o gênero lenda foi demonstrado pela contação das histórias, tivemos a preocupação de fazer a interdisciplinaridade com as disciplinas de Geografia e História, aumentando a potencialidade dos conhecimentos expostos e a serem internalizados. Nesse sentido, os textos contados aos educandos foram selecionarmos com base em critérios que levassem os mesmos a despertarem a curiosidade no imaginário e que também trouxessem elementos que ampliassem o leque de conhecimentos acerca da região originária da lenda a ser contada.

Nesse sentido, na atividade de número 3, três estudantes foram escolhidos pela turma para a realização da contação das lendas. A primeira lenda contada foi a do boto cor de rosa. Nela colocamos em evidência aspectos geográficos, como os rios da Amazônia, questões étnicas, uma vez que a narrativa escolhida apresenta a figura indígena e elementos sociais na representação dos povos ribeirinhos. A segunda foi a da baleia adormecida, tipicamente do estado do Piaú, especificamente da cidade de Valença. Sua contação foi iniciada com um aluno que mostrou aos colegas a localização geográfica da cidade por meio do mapa do estado do Piauí para que os alunos tivessem a noção de localização. 
Prática Educativa na Biblioteca Escolar: um trabalho a partir do gênero textual lenda

Por fim, tivemos a contação da lenda do pé-de-garrafa, outra genuinamente piauiense. Após a contação, por meio de voto, estabeleceu-se a lenda que caberia a cada atividade a ser desenvolvida posteriormente. Desse modo, decidiu-se pela seguinte ordem: O boto cor de rosa para a escrita da produção coletiva, a baleia adormecida para a produção individual e a do pé-de-garrafa para a criação de desenhos.

$\mathrm{Na}$ produção coletiva (Atividade 4), os alunos, em suas cadeiras, no espaço da biblioteca, lançavam opiniões a partir da contação do colega escolhido. Nós, na posição de mediador, íamos organizando as ideias e consequentemente o texto no quadro de acrílico. Nessa ocasião, percebemos muito entusiasmo, e este acreditamos que tenha se dado pelo fato de os alunos se sentirem valorizados, já que todas as ideias proferidas por eles eram debatidas, esclarecidas e incluídas no texto evidenciado no quadro, tornando-os assim, autores da produção desenvolvida.

$\mathrm{Na}$ produção individual (Atividade 5), observamos resistência em seu desenvolvimento por parte de alguns. Em contrapartida, outros se mostraram bem criativos, inserindo em suas produções elementos não presentes na lenda narrada pelo colega no ato da contação, demonstrando-nos um desenvolvimento da imaginação nunca antes evidenciado em nossa experiência com a turma.

\section{Atividade de Número 5}

Observamos que nesta atividade a atenção dos discentes foi quase que total, talvez pelo fato de esta ser a mais esperada por eles, já que a maioria quando estabelecido na divisão dos grupos, optou por ela.

Após a contação da lenda, vários foram os questionamentos que emergiram como: Se era verdade?, Se poderia existir animais com o pé-de-garrafa?. Como consequência, todas as dúvidas foram sanadas na medida em que íamos estabelecendo relações com as ponderações levantadas entre a realidade e o lado fantasioso característico das lendas.

Um fato de grande relevância e merecedor de destaque que nos ajudou neste processo de entendimento pelos alunos foi quando um deles, de forma bem esclarecedora, caracterizou o objeto garrafa como algo comercial e o corpo de um animal como algo que a natureza cria. 
Lucas Veras de Andrade

Não podendo um animal como o da lenda contada, ser criado metade (corpo) pela natureza e a outra (garrafa) pela indústria.

A afirmação da impossibilidade da existência de um ser com estas características por este aluno nos faz inferir sua internalização de um dos conceitos essenciais do gênero textual lenda: a relação fantasiosa com o mundo real. Depois de terminado o processo de criação dos desenhos, convidamos cada aluno para apresentar sua arte e percebemos que muitos foram os significados atribuídos, desde ideias inovadoras com enfoque contemporâneo até opiniões acerca da melhor forma de um indivíduo se salvar de uma situação como a demonstrada pela lenda.

\section{Atividade de Número 6}

Nesta, a lenda escolhida para o desenvolvimento das atividades foi a do cabeça-decuia que conta a história do pescador Crispim. O grupo encarregado da atividade ficou responsável por toda a criação dos personagens, cabendo a nós a confecção da estrutura do teatro. Desse modo, os alunos manusearam para a elaboração dos bonecos: cartolinas e palitos de picolé.

$\mathrm{Na}$ data reservada para a elaboração desta atividade, um aluno escolhido pela turma fez leitura em voz alta para que os outros pudessem compreender a lenda e, a partir desta, confeccionar o material a ser apresentado. Assim foram montados dois personagens para a realização do teatro com varas, bem como o cenário em torno do qual girava o enredo da história.

Desse modo, apresentou-se o teatro mediante a leitura da lenda por um aluno, enquanto que outros quatro manobravam os cenários e os bonecos criados. 
Prática Educativa na Biblioteca Escolar: um trabalho a partir do gênero textual lenda

\section{Atividade de Número 7}

Esta atividade foi contemplada a partir de sete etapas até a sua culminância final com a apresentação da lenda da vitória régia. Para a realização das etapas, fundamentamo-nos nas orientações de Brasil (1998), utilizamo-nos ainda de algumas de suas nomenclaturas. Desse modo, a primeira etapa foi desenvolvida ainda no estágio inicial do projeto, especificamente na atividade de número dois, em que mediante a opinião dos discentes acertou-se as lendas a serem trabalhadas em cada atividade proposta.

Nesta nos preocupamos com a escolha de bons textos, e mediante leitura coletiva para os alunos, procuramos fazer sempre que pertinente adaptações frente às opiniões dos estudantes, uma vez que o texto lendário não se apresenta sob a forma de um texto para ser dramatizado. Logo após tivemos a etapa que denominamos de sequência de leituras, momento em que os discentes, orientados por nós, dividiram o texto em "atos" e, por conseguinte, em cenas. Nesta etapa, dividiu-se a turma em três grupos e propusemos aos alunos a divisão de tarefas: cada um dos grupos ficaria responsável por elaborar e empreender uma ação para a culminância desta, como a confecção de roupas, construção do cenário, escolha e invenção de personagens, caso necessário.

A terceira etapa foi de difícil desenvolvimento, pois nela deu-se a escolha dos alunos que representariam os personagens e essa gerou certo conflito entre os discentes. Tal opção deu-se pela própria turma, que escolheu de forma democrática aqueles alunos que, na visão deles, melhor representariam os papéis a serem interpretados na peça teatral. Uma vez definidos quem faria as interpretações, partiu-se para as leituras com os respectivos alunos para correções ou eliminação de problemas de interpretação.

Uma etapa bastante interessante a nosso ver foi a que denominamos de Alunado em ócio criativo. Nela os alunos que ficaram sem papéis na dramatização nos deram valiosas contribuições, pois por iniciativa deles, várias atividades foram desenvolvidas para a efetivação desta atividade. Esta estratégia possibilitou que todos participassem, pois para nós é importante a valorização de todos e o trabalho de diversas formas.

A quinta e a sexta etapas estiveram unidas. A primeira teve a marcação das falas dos personagens bem como a marcação do momento em que cada personagem entraria no cenário da encenação. A segunda foi destinada aos ensaios que se constituíram em uma semana, ao final reunimos o grupo e fizemos uma avaliação para que fossem corrigidos os erros e 
Lucas Veras de Andrade

aprimorados os acertos. Por fim, tivemos a encenação que teve como expectadores toda a comunidade escolar em apresentação no pátio da escola.

\section{Análise e discussão dos resultados: a visão dos alunos e a nossa diante dos escritos e observações}

Com a finalização das atividades, todos os alunos foram instigados a responder a seguinte pergunta em questionário: Você gostou do projeto e das atividades desenvolvidas?. Obtivemos respostas de duas naturezas. Alunos que se manifestaram negativamente e outros que demonstraram estarem bem satisfeitos. No primeiro grupo evidenciado, apenas $4 \%$ (quatro por cento) dos discentes se evidenciaram de forma negativa. Suas motivações para tal justificativa foram: a leitura em voz baixa e lentidão do colega no momento da contação das lendas, a indisciplina dos colegas e as conversas paralelas. No que se refere ao restante dos alunos, todos se manifestaram positivamente, representando um total de $96 \%$ (noventa e seis por cento), ou seja, a grande maioria.

Nos discursos deste último grupo encontramos falas que demonstram o alcance dos objetivos deste projeto, como pode ser evidenciado a seguir:

\footnotetext{
Eu gostei porque nos ajudou a melhorar nossa leitura e também nossa escrita. Também eu li um monte de coisa de onde eu moro. (Aluno A).

Eu gostei porque teve a leitura do boto, e das coisas de Teresina. Gostei muito também de ir à biblioteca, lá é bem legal e tem um monte de coisa. (Aluno B).

Porque foi divertido, legal e aprendemos muitas coisas, ás vezes eu achei cansativo mais eu li muitos livros e agora eu sei de bem mais coisas, principalmente do Piaú́. Também escrevi muito e gostei muito de fazer textos. (Aluno C).
}

Quando o aluno A menciona sua melhora na leitura e escrita, seu discurso vai ao encontro do que pensamos sobre estes dois aspectos da aprendizagem: que eles dialogam a todo instante porque na medida em que se tem a vivência com a leitura, consequentemente sua escrita tende a melhorar, além de ampliar o repertório de palavras e conhecimento acerca das coisas. Ao afirmar "Também eu li um monte de coisa de onde eu moro", a concepção aqui de leitura converge a compreensão que Cardozo e Pelozo (2007, [p. web]) demonstram sobre o ato de ler. Segundo as autoras, "O ato de ler é imprescindível ao indivíduo, pois proporciona a inserção do mesmo no meio social e o caracteriza como cidadão participante”. 
Prática Educativa na Biblioteca Escolar: um trabalho a partir do gênero textual lenda

O mesmo entendimento do aluno A podemos observar no aluno $\mathbf{C}$ quando ele proferiu “"...] eu li muitos livros e agora eu sei de bem mais coisas, principalmente do Piauí’. O mesmo ainda nos chama atenção sobre o gosto que teve em produzir textos. O aluno B nos chamou atenção por ter apresentado de forma otimista e agradável o seu olhar sobre a biblioteca, ressaltando ser legal e a imensidade de "coisas", que aqui entendemos um mundo de fantasia e atividades que podem ser encontradas e desenvolvidas.

Embora uma minoria do grupo tenha evidenciado não ter gostado do projeto pelos motivos já mencionados, em nenhum momento observou-se apatia no desenvolvimento das atividades por eles realizadas. Acreditamos que os aspectos mencionados fazem parte. Lógico que ao iniciarmos projetos desta natureza esperamos a colaboração de todos, no entanto, somos surpreendidos com comportamentos discentes que não esperávamos. O que cabe a nós nessas situações é elaborarmos estratégias que permitam chamar atenção destes que nos apresentam resistências. Nas falas dos alunos A e B ainda podemos perceber a questão identitária, que entendemos como um processo de autoconhecimento sobre si enquanto ser que faz parte de uma sociedade.

Com relação ainda aos objetivos, evidencia-se a partir de nossos escritos que os alunos demonstraram um nível de aprofundamento teórico com relação às lendas além do esperado, aliás, além do esperado para a faixa etária, pois nas produções escritas demonstraram segurança e aspectos de diversas naturezas, aspectos em nível de conteúdo que não foi explorado por nós no desenvolvimento do projeto. A mesma inferência temos com relação ao objetivo 2, demonstrado na introdução, ou seja, permitir aos discentes o conhecimento de diversas lendas que puderam ser aprofundadas a partir da leitura das obras. Os alunos tiveram um trabalho riquíssimo de pesquisa por iniciativa própria, embora tenham sido escolhidas apenas cinco lendas para serem trabalhadas em nosso projeto, eles traziam outras leituras e sempre tínhamos a preocupação de estar sanando qualquer dúvida em relação ao material que era levado, sendo ainda feito leitura coletiva desses textos.

É inegável o alcance do objetivo três, os discursos aqui já demonstrados falam por si sós. O desenvolvimento das habilidades em grupo foi o que mais nos deixou satisfeitos, uma vez que atividades coletivas antes deste projeto não se evidenciavam em sala, já que os alunos se mostravam agressivos e intolerantes com relação às opiniões dos colegas. Percebemos por parte deles nas atividades empreendidas, um interesse nunca antes demonstrado e o respeito 
Lucas Veras de Andrade

diante daqueles que evidenciavam suas opiniões mesmo não acatadas pelo grupo, habilidade esta de difícil alcance pela própria faixa etária dos alunos.

Com relação ao nosso último objetivo, o de reativar o espaço da biblioteca escolar na instituição na qual realizamos o projeto, é algo que só vamos alcançar a médio e longo prazo já que é de nossa intenção continuar a realizar projetos desta natureza. Avanços já foram presenciados até antes mesmo da finalização do projeto. Observa-se alunos em horas vagas frequentando a biblioteca, desenvolvendo assim, o hábito da leitura, uma vitória que já nos foi evidenciada ainda na fase inicial, visto que muitos alunos ali visitavam esse espaço tão importante no contexto pedagógico pela primeira vez.

Cabe a nós desmistificar o conceito bem como a usabilidade da biblioteca escolar, já que este espaço ainda é mal compreendido pelos alunos e o pior, mal utilizado pelos professores. A nossa intenção é chamar atenção para este espaço já que oportuniza aos discentes a internalização de informações, faz do aluno um ser ativo em sua aprendizagem e torna-se para ele uma referência que aguça a curiosidade, desperta a criticidade e mais que tudo, se institui como um agente transformador.

\section{Considerações finais}

Aliar projetos ao contexto de sala de aula é uma oportunidade riquíssima para assimilação de conteúdos. Apesar das dificuldades encontradas no caminho, os resultados já evidentes superaram as expectativas. O percurso metodológico adotado se mostrou muito significativo tanto pra nós enquanto executores, como para os alunos no que se refere à assimilação dos conteúdos, servindo ainda como meio de interação e incentivo ao uso do espaço da biblioteca escolar e o desenvolvimento da leitura.

Uma de nossas conclusões é que a biblioteca escolar pode constituir-se como um ambiente de ação cultural mesmo que os recursos sejam incipientes. A biblioteca em que desenvolvemos nosso projeto não conta com recursos próprios muito menos com recursos humanos para mediar e desenvolver toda a potencialidade que este espaço pode dar de retorno às atividades desenvolvidas pelos professores em sala e de todo o contexto de uma escola, entretanto, nossa iniciativa é um exemplo vivo que ela pode sim cumprir sua missão mesmo diante dessas situações citadas. Agora é necessário que os membros dos contextos educacionais, sejam professores, gestores ou mesmo os bibliotecários escolares (profissional

Bibl. Esc. em R., Ribeirão Preto, v. 4, n. 1, p. 75-95, 2015. 
Prática Educativa na Biblioteca Escolar: um trabalho a partir do gênero textual lenda

inexistente no contexto educacional público no município de Teresina) reconheçam toda a potencialidade desta.

Desse modo, cremos na ideia de que a apresentação dos resultados aos professores vinculados a Escola Municipal Professora Alda Rodrigues Neiva, possa motivá-los a desenvolverem projetos desta natureza, colaborando para a inserção da biblioteca escolar no contexto das atividades da sala de aula e na rotina dos alunos ao seu uso, uma vez que entendemos que ela é sua complementação, uma extensão do espaço leitor de sala de aula.

Agradecimentos: Para Vilma Sampaio (Professora Formadora de Língua Portuguesa) do Centro de Formação Odilon Nunes, vinculado a Secretaria Municipal de Educação de Teresina, pelos conhecimentos repassados durante o nosso percurso de formação neste Centro.

Aos Amigos e Professores: Helison Daniel de Sousa Lima e José Augusto Sousa Almeida pelas leituras e releituras do manuscrito e por sempre se doarem as minhas ideias de "Professor Pesquisador".

Aos meus amados alunos pela convivência e oportunidade de crescimento pessoal e profissional, inclusive como pesquisador.

Aos gestores da Escola Municipal Alda Rodrigues Neiva por permitir que a escola seja "invadida" por minhas ideias e sempre quando solicito permitir que o espaço desta, seja meu lócus de pesquisa.

Bibl. Esc. em R., Ribeirão Preto, v. 4, n. 1, p. 75-95, 2015. 
Lucas Veras de Andrade

\section{Referências}

BRASIL. Ministério da educação e do Desporto. Fundo Nacional de Desenvolvimento da Educação. Manual pedagógico da biblioteca da escola. Brasília: [Ministério da educação e da Cultura], 1998.

CAMPELLO, B. A competência informacional na educação para o século XXI. In: et.al. A Biblioteca escolar: tema para uma prática pedagógica. 2. ed. Belo Horizonte: Autêntica, 2005. p. 9-11.

CARDOZO, G. C; PELOZO, R. C. B. A importância da leitura na formação do indivíduo. Revista Científica Eletrônica de Pedagogia, São Paulo, ano 5, n. 9, semestral, 2007. Disponível em: <www.revista.inf.br/pedagogia09/pages/artigos/edic09-anov-art03.pdf $>$. Acesso em: 10 set. 2011.

CASCUDO, L. C. Lendas brasileiras para jovens. 3. ed. São Paulo: Gaia, 2009.

LAVILLE, C. A construção do saber: manual de metodologia da pesquisa em ciências humanas. Porto Alegre: Artes médicas, 1999.

OLIVEIRA, S. B. A; CASTRO, J. C. J. Textos: gêneros. In: Usando textos em sala de aula: tipos e gêneros textuais. 3. ed., rev. Brasília: Instituto Alfa e Beto, 2008. p. 74-76.

Usando textos em sala de aula: tipos e gêneros textuais. 3. ed., rev. Brasília: Instituto Alfa e Beto, 2008.

RODRIGUES, J. L. P. Geografia e história do Piauí: estudos regionais. Teresina: Halley, 2004.

SILVA, R. J. Biblioteca escolar: organização e funcionamento. In: SOUZA, R. J. (Org.). Biblioteca escolar e práticas educativas: o mediador em formação. São Paulo: Mercado de Letras, 2009.

SOARES, J. F; ANDRADE, L. V.; SALES, W. N. O ambiente escolar e a atuação bibliotecária: um olhar de estagiários de Biblioteconomia no município de Teresina - PI. In: ENCONTRO REGIONAL DE ESTUDANTES DE BIBLIOTECONOMIA, DOCUMENTAÇÃO, CIÊNCIA DA INFORMAÇÃO E GESTÃO DA INFORMAÇÃO: Os novos campos da profissão da informação na contemporaneidade, 14., 2011, São Luís - MA. Anais eletrônicos... São Luís: UFMA, 2011. Disponível em: $<$ http://rabci.org/rabci/sites/default/files/O\%20AMBIENTE\%20ESCOLAR\%20E\%20A\%20 ATUA\%C3\%87\%C3\%830\%20BIBLIOTEC\%C3\%81RIA\%20um\%20olhar\%20de\%20estagi \%C3\%A1rios\%20de\%20Biblioteconomia\%20no\%20munic\%C3\%ADpio\%20de\%20Teresina \%20\%E2\%80\%93\%20PI.pdf>. Acesso em: 08 set. 2012.

TRIVINÕS, A. N. S. Introdução à pesquisa em ciências sociais: a pesquisa qualitativa em educação: o positivismo, a fenomenologia e o marxismo. São Paulo: Atlas, 1987.

VILlAS BOAS, M. Mistérios da Pindorama. Rio de Janeiro: Cultimix, 2000. 